\title{
Article \\ Phenomenon Analysis and Improvement of Magnetic Shield Fringe Effect on Wireless Power Transmission of EV
}

\author{
Yening Sun ${ }^{1, *}$, Yao Wei ${ }^{2, *}$ (D) and Yi Tian ${ }^{3}$ \\ 1 Department of Electrical and Information Engineering, Hebei Jiaotong Vocational and Technical College, \\ Shijiazhuang 050035, China \\ 2 Quanzhou Institute of Equipment Manufacturing, Haixi Institutes, Chinese Academy of Sciences, \\ Fuzhou 350002, China \\ 3 School of Electrical Engineering, Beijing Jiaotong University, Beijing 100044, China; 21117031@bjtu.edu.cn \\ * Correspondence: sunyening@stumail.ysu.edu.cn (Y.S.); weiyao@stumail.ysu.edu.cn (Y.W.)
}

check for updates

Citation: Sun, Y.; Wei, Y.; Tian, Y.

Phenomenon Analysis and

Improvement of Magnetic Shield Fringe Effect on Wireless Power Transmission of EV. World Electr. Veh. J. 2021, 12, 252. https://doi.org/ 10.3390/wevj12040252

Academic Editor: Zonghai Chen

Received: 19 October 2021

Accepted: 17 November 2021

Published: 25 November 2021

Publisher's Note: MDPI stays neutral with regard to jurisdictional claims in published maps and institutional affiliations.

Copyright: (c) 2021 by the authors. Licensee MDPI, Basel, Switzerland. This article is an open access article distributed under the terms and conditions of the Creative Commons Attribution (CC BY) license (https:// creativecommons.org/licenses/by/ $4.0 /)$.

\begin{abstract}
An increment of magnetic field strength inevitably appears at the shield edge if a magnetic shield is made of a soft magnetic material, and that increment becomes more serious if this shield is combined with the chassis of an electrical vehicle (EV). This phenomenon is caused by the fringe effect, which limits the transfer efficiency of the coupler for the wireless power transmission (WPT) systems of EV. This phenomenon, and its relationships with some parameters, are analyzed in this paper, and these relationships are fitted to estimate the increment for different shield structures. A magnetic shield structure to reduce the increment of the magnetic field strength and improve coupler efficiency is herein proposed. The effectiveness and correctness of the fitting curves and the advantages of the proposed shield structure are demonstrated by finite element analyses results.
\end{abstract}

Keywords: coupler; magnetic shield; fringe effect; WPT; EV

\section{Introduction}

In order to prevent serious air pollution, EV and hybrid EV (HEV) are widely used to replace the traditional fuel vehicle and reduce exhaust gas emissions. Since a large floor space and a contact-type charging rack are necessary for a charging pile or charging station, this building project requires large-scale investments, and the security is weak due to its possible poor contact [1]. WPT became a research hotspot in recent years to reduce cost and ensure security for the EV charging system [2]. WPT is mainly divided into static WPT and dynamical WPT. The former requires the charging process to start after the vehicle has stopped within a specified space, and the latter means that the vehicle can be charged during any operating state $[3,4]$. The coupler is the key equipment component of WPT, and has four main parts, including the primary coil, the primary magnetic shield, the secondary coil and the secondary magnetic shield. The primary side of the coupler is always installed underground and sends the high-frequency magnet field into the air. The secondary side of the coupler is installed below the chassis of the vehicle, which is shown in Figure 1; the magnetic field in the air can be received and converted into a high-frequency current to satisfy requirements of EV [5].

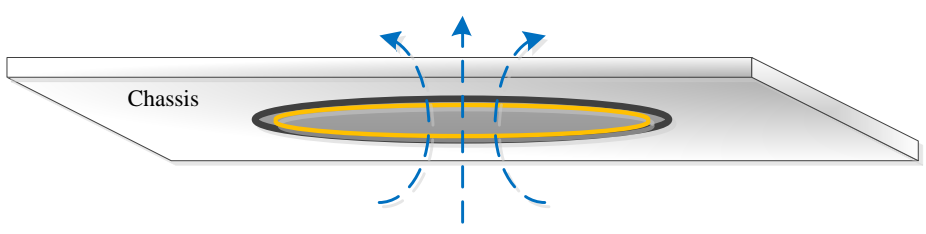

Figure 1. Sketch of EV chassis.

Two magnetic shields are adopted to summarize the magnetic field into the middle space between them for improved transfer efficiency [6]. Based on the typical circle and 
square type coils, many new coil shapes have been proposed to achieve better transfer efficiency, such as the double D-type (DD) [7], the double D-type quadrature (DDQ) [8], the bipolar pad (BP) [9], the tripolar pad (TP) [10], the quadruple pad (QP) [11], the taichitype [12] and some tridimensional-type coils [13,14]. Cost advantage and a lower leaked magnetic field were achieved with these new-type coils, as well as better stability and an anti-offset of the charging process.

The shape of the shield needs to be adjusted according to the coil shape, such as the cylindrical or pad shield for the circle coil [15], the quadrangular layer for the square coil $[16,17]$ and the strip-type layers for DD and DDQ coils [18,19]. These shapes are commonly used due to their low costs and simple structures. Excepting these conventional structures of shields, some novel structures are presented to improve efficiency. An aluminum plate, ring and ferrite bars are combined as a shield in $[20,21]$ and operated with a circle coil and a DD coil, respectively. Aluminum and ferrite are the commonly used materials for shields, and double-layer and multi-layer shields with multiple materials are used to improve shielding efficiency of magnet fields with different frequency characteristics [22]. Some new-type and composite materials with larger relative permeability also can be applied, such as the nanocrystalline material in [23] and the hybrid high-temperature superconductor/ferromagnetic material in [24].

If a soft magnetic material is adopted to make the secondary side shield, the magnet field strength at the edge of the shield will be increased according to the results of finiteelement analysis and experiments. Since the chassis is always made from a hard magnetic material such as steel or aluminum alloy, the shield can be seen as a double layer. This phenomenon becomes more serious if the adopted material has larger relative permeability and the shield has double or multiple layers; furthermore, the transfer efficiency is affected due to the increased strength. This phenomenon has been named the fringe effect of shields, and it is necessary to improve shield structure to solve this problem.

For the secondary shield of the soft magnet material, the relationships between the increment of the magnet field strength by the fringe effect and some parameters including the radius, depth, relative permeability and input power of the coupler are obtained in this paper by the linear fitting and correlation analysis methods to estimate the increment values due to the influence of the fringe effect. Based on these relationships and estimated value, an improved shield with an extended part is proposed to prolong the radius indirectly and reduce the influences of the fringe effect. According to the results of the finite element analyses, the correctness and effectiveness of the proposed structure were verified, and the advantages, including reduced influence of the fringe effect, resistance to the horizontal offsets and improved transfer efficiency achieved, in comparison with the conventional shield structure.

This paper is organized as follows: In Section 2, basic structures of WPT and its coupler are introduced. In Section 3, the phenomenon of the fringe effect and its relationships with some shield and circuit parameters are obtained. In Section 4, the proposed shield structure is shown and verified by the finite element analysis. In Section 5, a conclusion is summarized for this paper.

\section{Structure of Coupler}

The basic structure of a WPT system for EV is shown in Figure 2, which includes a power-frequency rectifier and its filter, a high-frequency inverter, a primary side compensation circuit, a secondary side compensation circuit, a high-frequency rectifier and its filter and loose coupler are combined as mainly as a WPT system, where the loose coupler is the key for transferring energy by high-frequency magnetic field. The basic structure of the coupler is shown in Figure 3, which mainly includes primary and secondary coils and their shields. 


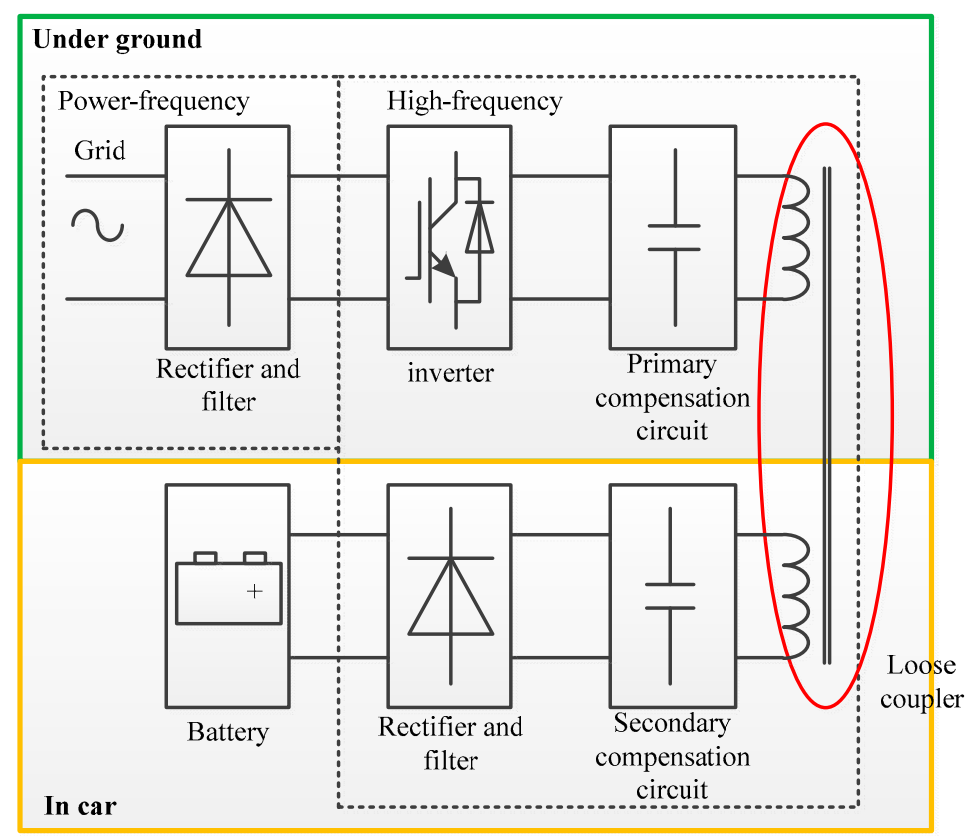

Figure 2. Basic structure of a WPT system.

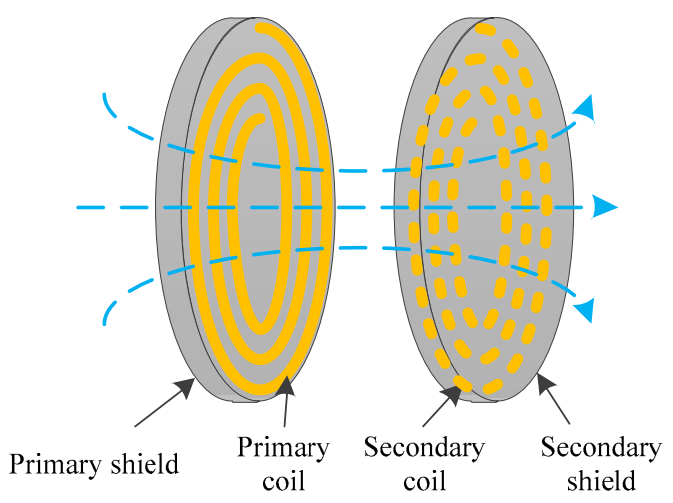

Figure 3. Basic structure of the loose coupler.

The primary side circuit, coil and shield are always installed at the ground, and the secondary is installed on the EV. These shields make the magnetic field summarize within their middle range to reduce the wasted power in the air and decrease the influence on the EV.

\section{Phenomenon and Relationships Analyses}

\subsection{Phenomenon}

A circuit coil and a cylindrical shield of aluminum are selected as an example, and used as the coupler secondary side. As shown in Figure 4, most of the magnetic field lines are reflected at the surface of the shield because of the lower relative permeability of aluminum.

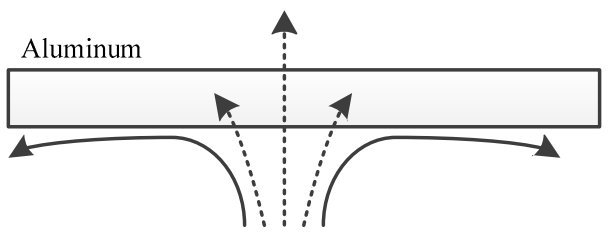

Figure 4. Magnetic field lines of shield of aluminum. 
As shown in Figure 5, most of the magnetic field lines are refracted and entered into the shield if the material is changed into ferrite.

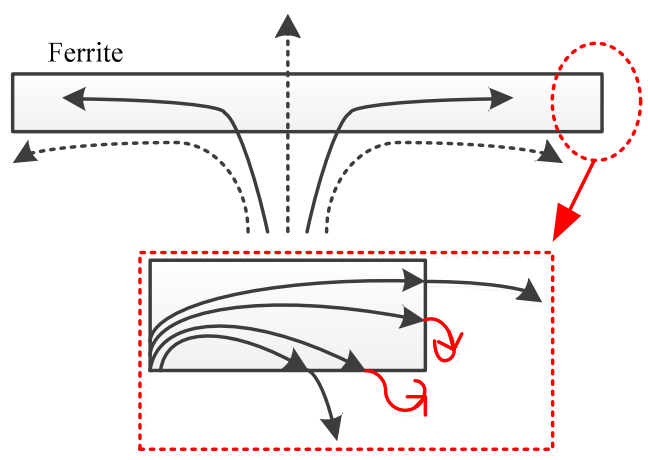

Figure 5. Magnetic field lines of shield of ferrite.

In order to clearly observe the magnetic field distributions by the soft and hard magnetic materials, distribution diagrams and curves of magnet field strength by aluminum and ferrite are shown in Figures 6 and 7, respectively, by the finite element analysis. They show that due to the influence of the fringe effect, the magnet field is gathered at the edge of the shield of the ferrite because it is a kind of soft magnetic material, and its magnet field strength obviously increases at the edge compared with the aluminum. This phenomenon results in the longer length of the closed magnet field lines. More energies are used to generate magnetic field to transfer power.

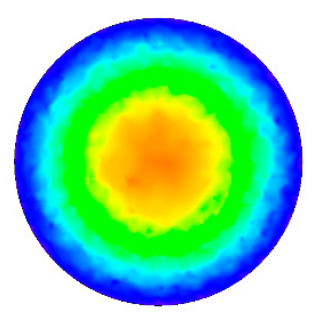

(a)

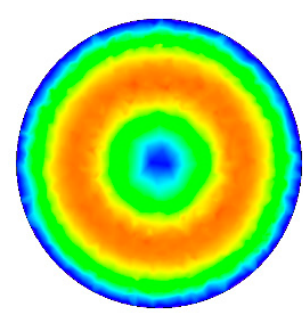

(b)

Figure 6. Distribution diagrams of magnetic field strength for different materials. (a) Aluminum. (b) Ferrite.

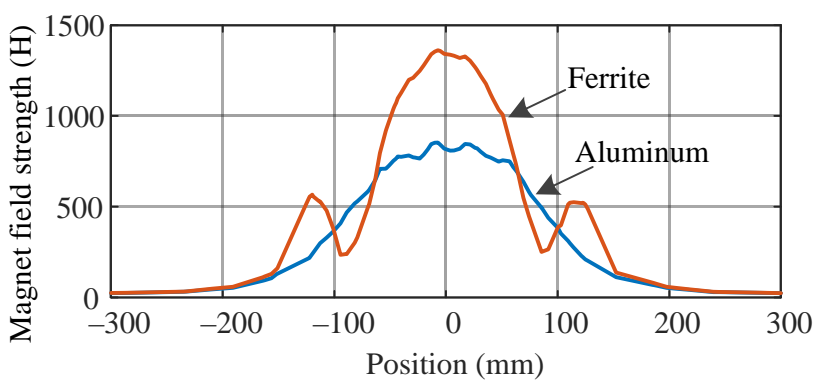

Figure 7. Curves of magnetic field strength for different materials.

As mentioned above, since the materials of chassis belong to hard magnetic material, the combination of the ferrite and the chassis becomes as a double-layer shield. For a shield with double and multiple layers, more energies are summarized into the inner layer, and the fringe effect becomes more serious because of less relative permeability of the outer layer. 


\subsection{Relationships for Fringe Effect}

A cylindrical shield is adopted to judge relationships between the fringe effect and some selected variables of the shield, including radius, depth, input power and relative permeability. The initial parameters of the shield are listed in Table 1.

Table 1. Initial parameters of the secondary shield.

\begin{tabular}{ccc}
\hline Symbol & Quantity & Values \\
\hline$r$ & Radius & $120 \mathrm{~mm}$ \\
$d$ & Depth & $1 \mathrm{~mm}$ \\
$\mu_{r}$ & Relative permeability & 2500 \\
$p_{i}$ & Input power & $10 \mathrm{~W}$ \\
\hline
\end{tabular}

\subsubsection{Radius Influences}

Under the condition of the fixed $d, \mu_{r}$ and $p_{i}$, make the radius $r$ change from $112 \mathrm{~mm}$ to $140 \mathrm{~mm}$. Some of the magnetic field strength curves are shown in Figure 8 (Complete testing results are listed in Figure A1 in the Appendix A). The increasing range of the magnetic field strengths are involved during $(-150,-100)$ and $(100,150)$, and the coupler structure is symmetrical. The maximum and average values from $100 \mathrm{~mm}$ to $150 \mathrm{~mm}$ are tested and shown in Figure 9. According to these figures, the maximum and average values decrease with the increment of radius, and the location of the maximum value always appeared at the shield edge.
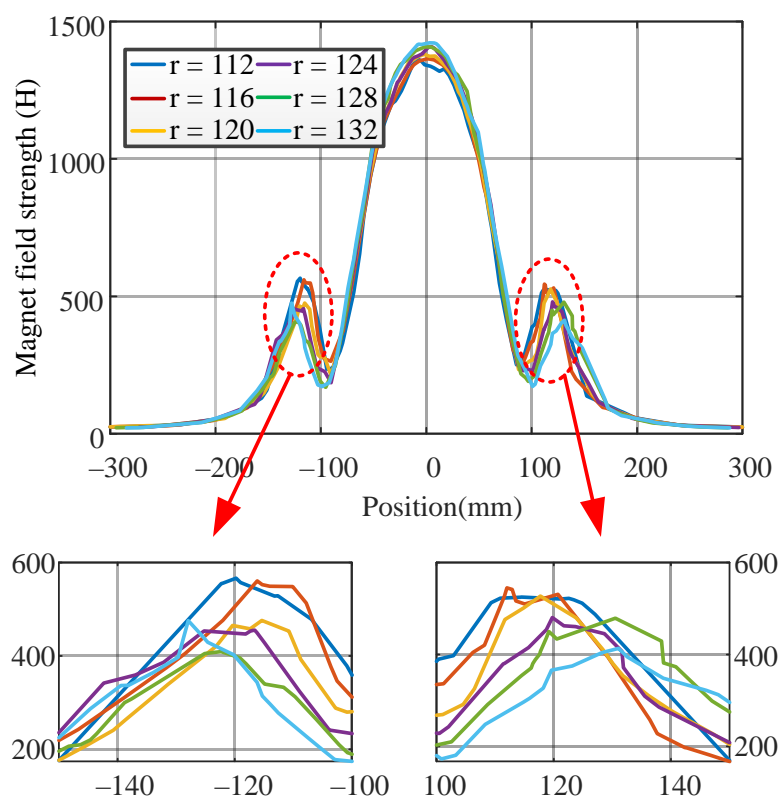

Figure 8. Magnetic field strength curves of shields with different radius.

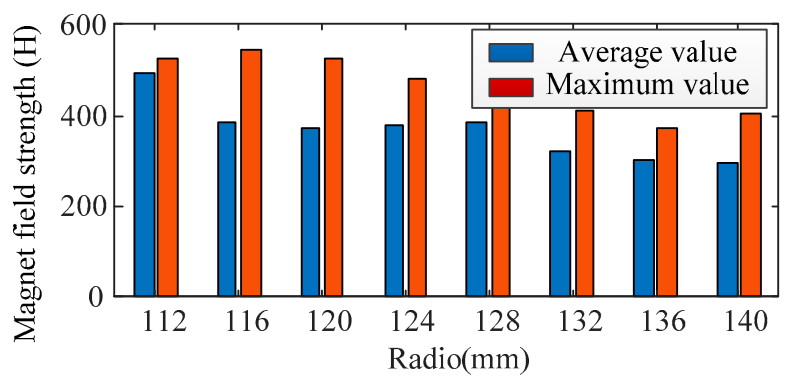

Figure 9. Maximum and average values of magnetic field strength due to the fringe effect with different radius. 


\subsubsection{Depth Influences}

Similarly, make the depth change from $0.5 \mathrm{~mm}$ to $4 \mathrm{~mm}$. Some of the magnet field strength curves are shown in Figure 10 (complete testing results are listed in Figure A2 in the Appendix A), and the maximum and average values from $100 \mathrm{~mm}$ to $150 \mathrm{~mm}$ are shown in Figure 11. They show that the magnet field strengths have similar curves, and the fringe effect is not obviously affected by the shield depth.
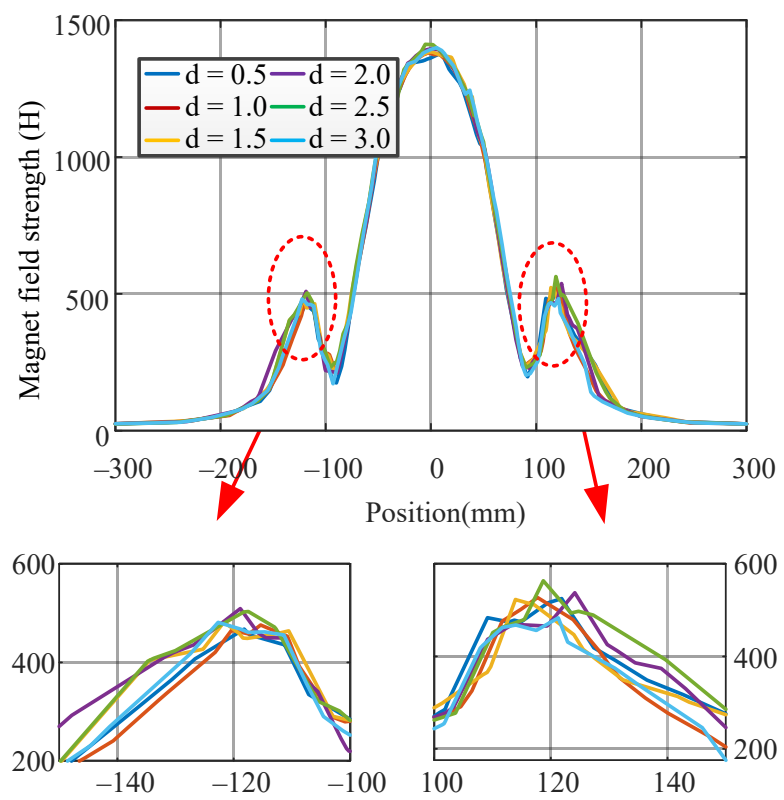

Figure 10. Magnetic field strength curves of shields with different depths.

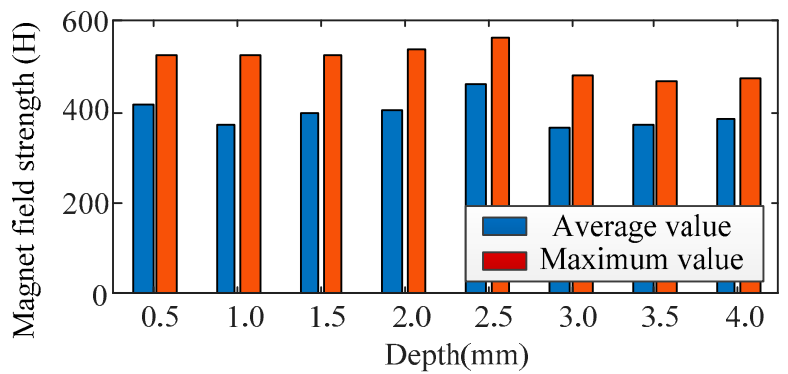

Figure 11. Maximum and average values of magnetic field strength due to the fringe effect with different depths.

\subsubsection{Input Power Influences}

The input power is changed from $5 \mathrm{~W}$ to $40 \mathrm{~W}$, and some of the magnet field strength curves and their maximum and average values are shown in Figures 12 and 13, respectively (complete testing results are listed in Figure A3 in the Appendix A). They show that the magnet field strengths have increased obviously, due to the fringe effect, with the increment of input power. 

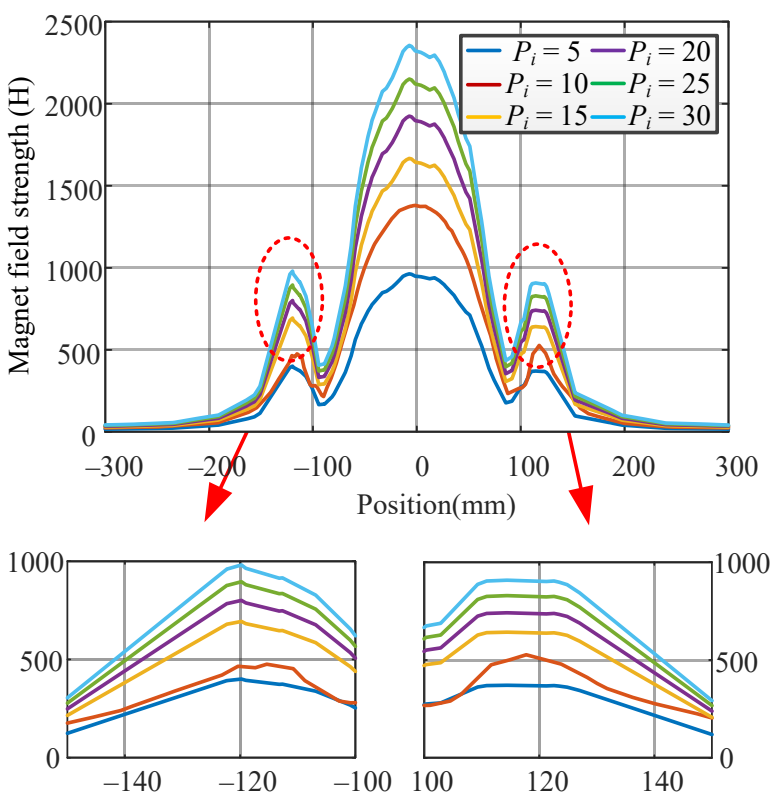

Figure 12. Magnetic field strength curves of shields with different input powers.

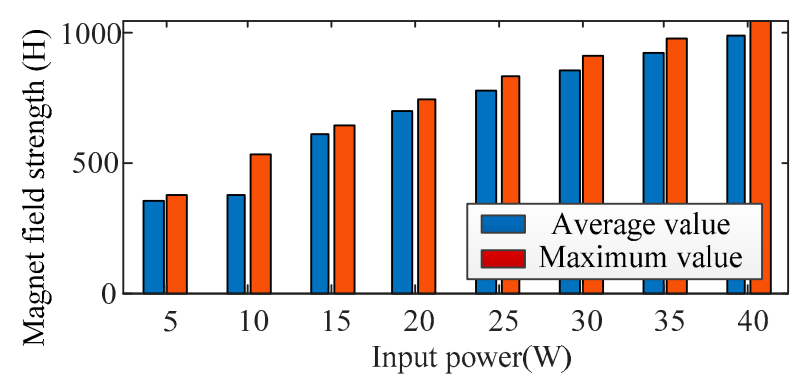

Figure 13. Maximum and average values of magnetic field strength due to the fringe effect with different input powers.

The ratios of the maximum values in $(100,150)$ to the maximum values in $(-300,300)$ are shown in Figure 14. It shows that most of these radio values are about 0.386 , and the relationship between the fringe effect and input power is a nearly positive proportion.

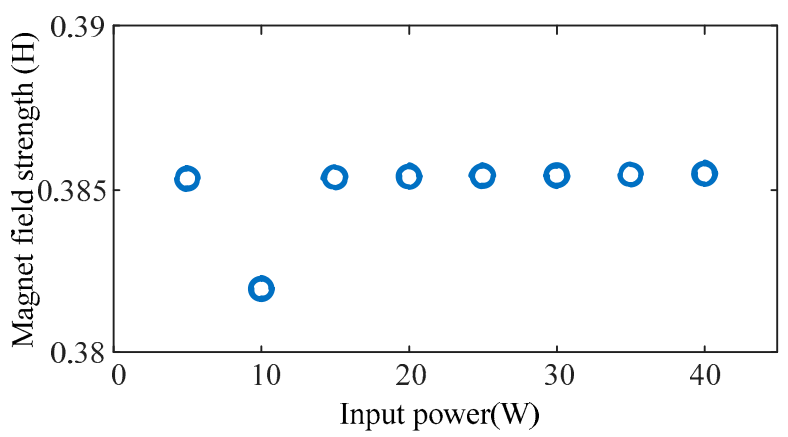

Figure 14. The ratios of the maximum values in $(100,150)$ to the maximum values in $(-300,300)$.

\subsubsection{Relative Permeability Influences}

Some common MnZn ferrites with relative permeabilities as 1200, 2500, 3000, 5000 and 7500; and NiZn ferrites with relative permeabilities as 250, 500, 900 and 1200 are adopted to test the influences-the testing results of the former ferrites are shown in Figures 15 and 16. They show that the magnet field strength is increased with the increment of relative permeability, but the rising trend of the magnet field strength becomes slower. 

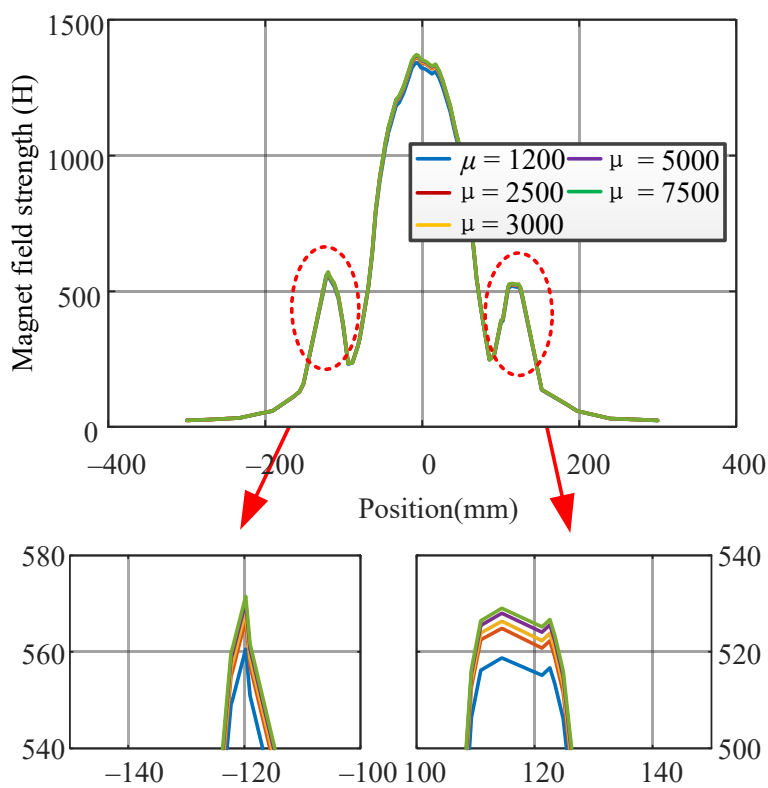

Figure 15. Magnetic field strength curves of shields of MnZn with different relative permeabilities.

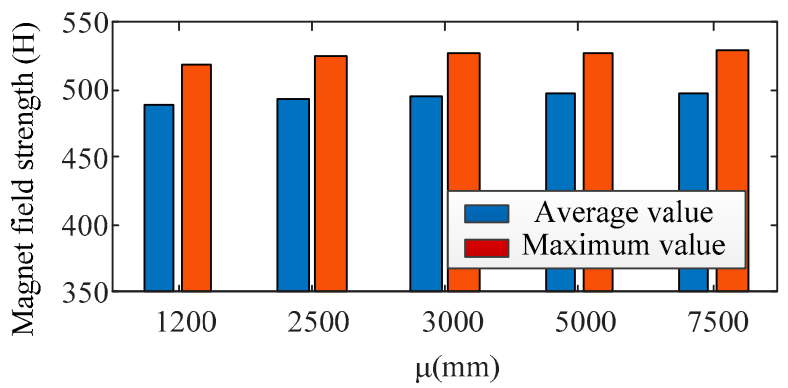

Figure 16. Magnetic field strength curves of shields of MnZn with different depths and different relative permeabilities.

Under the same conditions, the material is changed to NiZn ferrite, and the testing results are shown in Figures 17 and 18, respectively.
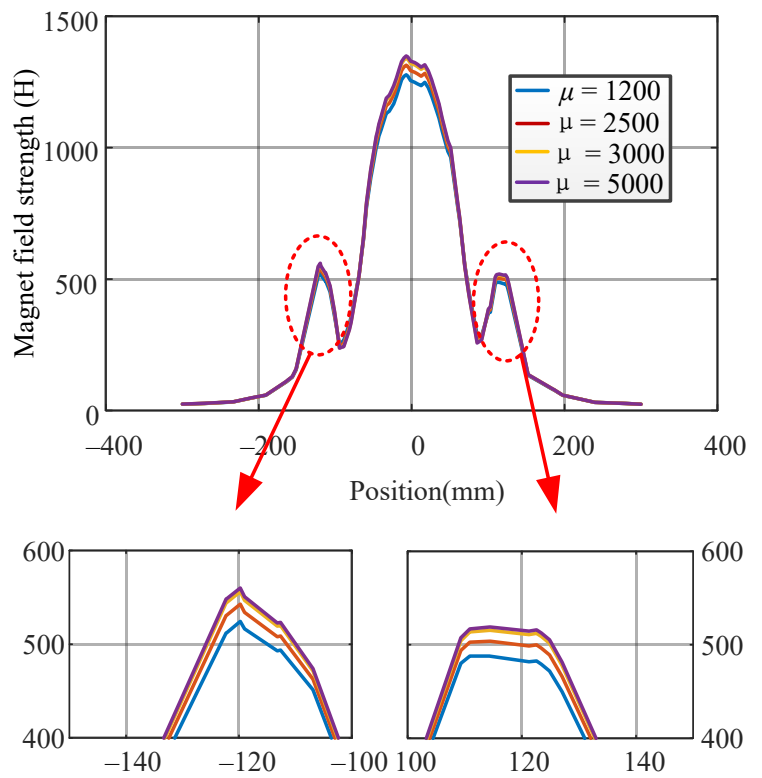

Figure 17. Magnetic field strength curves of shields of NiZn with different relative permeabilities. 


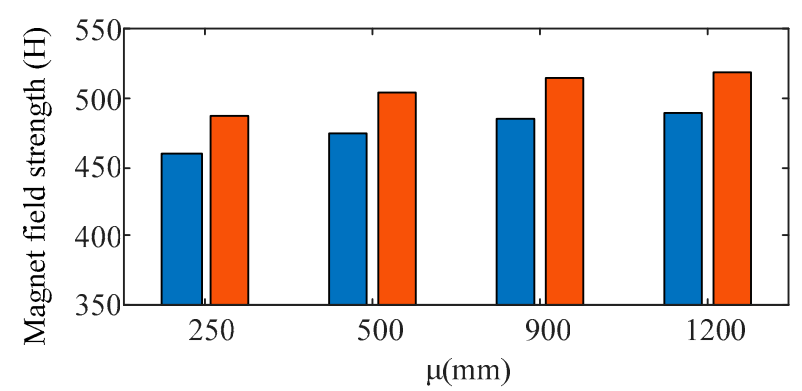

Figure 18. Magnetic field strength curves of shields of NiZn with different depths and different relative permeabilities.

\subsection{Correlation Analyses and Linear Fitting}

The Pearson, Kendall and Spearman correlation analyses are used to obtain correlation coefficients for these selected variables, and the results are listed in Table 2. According to the table, input power and relative permeability have significant influences on the fringe effect, and the influence of the radius is less than them. The influence of depth almost has no worth in statistical analysis because of the large significance value.

Table 2. Correlation analysis results.

\begin{tabular}{ccccc}
\hline & Radius & Depths & Input Powers & Relative Permeabilities \\
\hline Pearson correlation & -0.898 & -0.243 & 0.979 & -1 \\
Pearson significance & 0.002 & 0.562 & 0.000 & - \\
Kendall correlation & -0.786 & -0.214 & 1.000 & 1.000 \\
Kendall significance & 0.006 & 0.458 & 0.000 & 0.000 \\
Spearman correlation & -0.905 & -0.429 & 1.000 & 1.000 \\
Spearman significance & 0.002 & 0.289 & 0.000 & 0.000 \\
\hline
\end{tabular}

${ }^{1}$ The Pearson correlation analysis only suit for the evenly spaced variables.

Based on RLS, linear fitting is used to obtain a $k$-order polynomial to replace the trend of a group of sampling points [25]. The polynomial is:

$$
B_{f e}=\sum_{i=0}^{k} a_{i} x^{k-i}
$$

where $a_{i}$ is the coefficients, and $x$ is the selected variables.

According to the confidence intervals, the order $k$ is selected as 3, 4 and 2 for $r, p_{i}$ and $\mu_{r}$ to consider all of the sampled points. Fitting results are shown in Figures 19-21, respectively, and their coefficients are listed in Table 3. The confidence intervals in these figures involve all of the sampled points and the fitting results are credible.

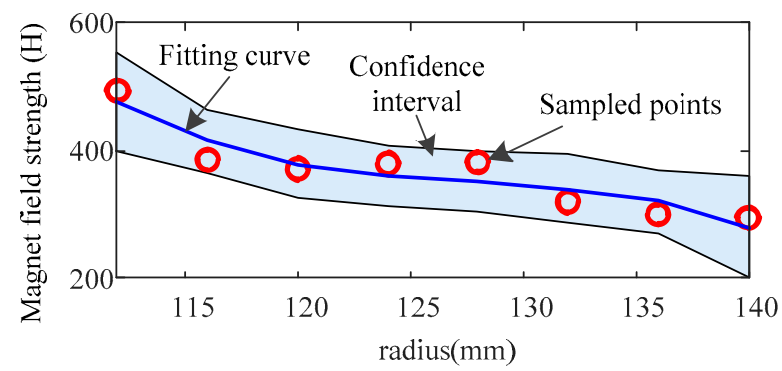

Figure 19. Fitting curve and its confidence interval of different radius. 


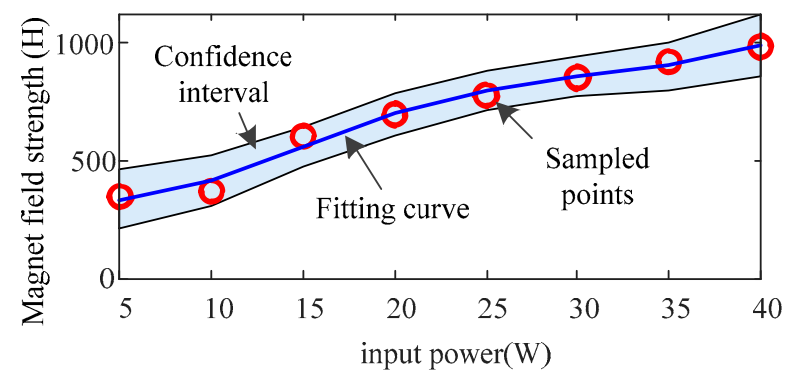

Figure 20. Fitting curve and its confidence interval of different input powers.

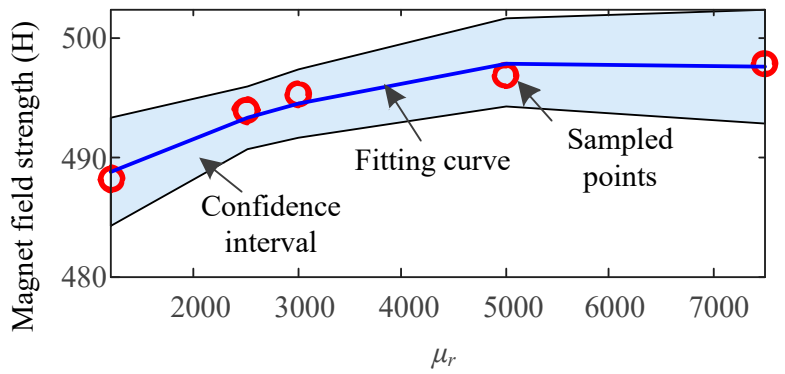

Figure 21. Fitting curve and its confidence interval of different relative permeabilities.

Table 3. Fitting coefficients.

\begin{tabular}{cccc}
\hline Coefficients & Values & Coefficients & Values \\
\hline$a_{1}$ for $r$ & -0.0242 & $a_{3}$ for $p_{i}$ & 6.1127 \\
$a_{2}$ for $r$ & 9.2502 & $a_{4}$ for $p_{i}$ & -45.0215 \\
$a_{3}$ for $r$ & -1182.99 & $a_{5}$ for $p_{i}$ & 434.4354 \\
$a_{4}$ for $r$ & $50,871.69$ & $a_{1}$ for $\mu_{r}$ & $-4.075 \times 10^{-7}$ \\
$a_{1}$ for $p_{i}$ & 0.0022 & $a_{2}$ for $\mu_{r}$ & 0.0049 \\
$a_{2}$ for $p_{i}$ & -0.2040 & $a_{3}$ for $\mu_{r}$ & 483.4461 \\
\hline
\end{tabular}

\section{Improvement Method}

\subsection{Physical Structure}

Since the space under the chassis is limited, the radius of the shield cannot be extended enough to eliminate the fringe effect. An extended part is added at the edge of the shield, and its structure is shown in Figure 22. This part can guide the magnet field to operate toward the primary coil and prolong the radius indirectly.

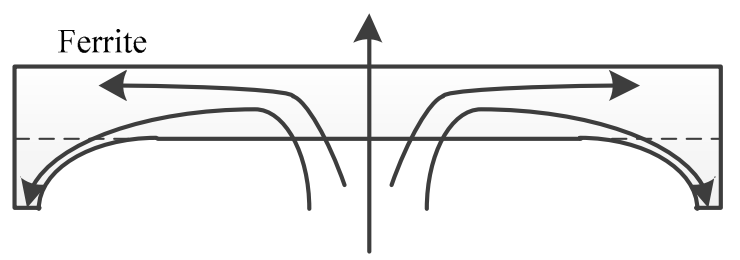

Figure 22. Structure of the proposed shield.

The physical dimensions of the proposed structure and the conventional structure are shown in Figure 23, where the radius $r$ and depths $d$ of two structures are the same values, and the inner radius $r_{i}$ is equal to the radius of secondary coil. 


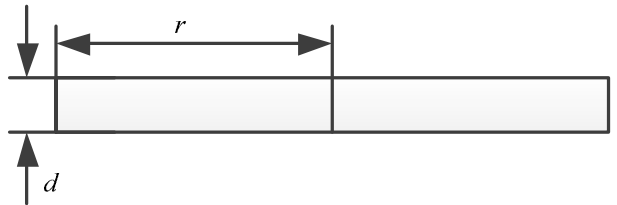

(a)

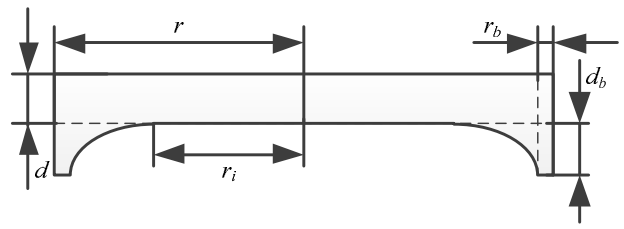

(b)

Figure 23. Physical dimensions of the shields. (a) Conventional structure. (b) Proposed structure.

\subsection{Finite Element Analysis}

The main parameters of the coupler with the proposed structure are listed in Table 4, and the model of secondary side is shown in Figure 24.

Table 4. Main coupler parameters with the proposed structure shield.

\begin{tabular}{ccc}
\hline Symbol & Quantity & Values \\
\hline$r$ & Radius & $120 \mathrm{~mm}$ \\
$d$ & Depth & $1 \mathrm{~mm}$ \\
$\mu_{r}$ & Relative permeability & 2500 \\
$p_{i}$ & Input power & $10 \mathrm{~W}$ \\
$r_{i}$ & Inner radius & $110 \mathrm{~mm}$ \\
$d_{b}$ & Extended depth & $5 \mathrm{~mm}$ \\
$r_{b}$ & Extended length & $10 \mathrm{~mm}$ \\
$r_{s}$ & Ring width of the secondary coil & $110 \mathrm{~mm}$ \\
$r$ & Radius of the coil line & $2.5 \mathrm{~mm}$ \\
$n_{s}$ & Number of turns of the secondary coil & 15 \\
$r_{p}$ & Ring width of the primary coil & $120 \mathrm{~mm}$ \\
$n_{p}$ & Number of turns of the primary coil & 17 \\
$d_{p s}$ & Distance between the primary and secondary coils & $50 \mathrm{~mm}$ \\
\hline
\end{tabular}

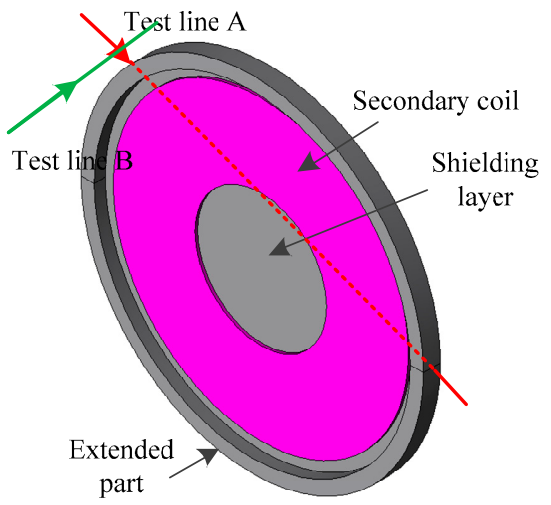

Figure 24. Secondary side of the finite element analysis model.

The distribution diagram of the magnet field strength of the secondary shield and its extended part are shown in Figure 25. It shows that the extended part covers the influenced edge of the fringe effect and some magnet fields are guided into this part to reduce the gathered magnet field. Since there are two types of materials located on the z-axis, the magnetic field strength curves are hard to analyze. The curves in Figure 26 are tested at $10 \mathrm{~mm}$ above the shields (which is the test line A in Figure 24) to observe fringe effect. The maximum value from $100 \mathrm{~mm}$ to $150 \mathrm{~mm}$ is 239.60 for the proposed structure. These figures show that the increments of magnet field strength at the left and right edges of the shield are reduced by the extended part. 


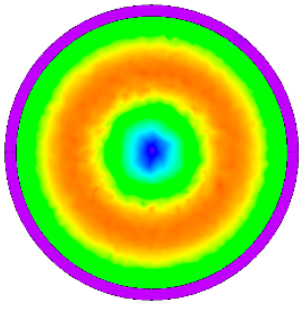

(a)

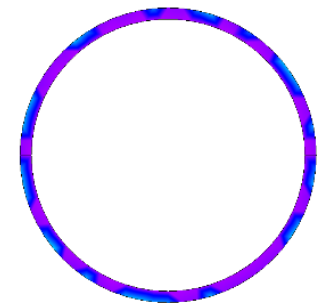

(b)

Figure 25. Distribution diagrams of magnetic field strength for the proposed structure. (a) Secondary shield. (b) Extended part.

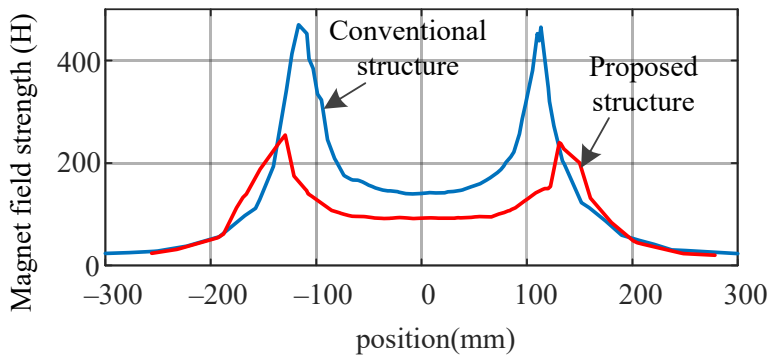

Figure 26. Magnetic field strength curves at $10 \mathrm{~mm}$ above the shields.

The test line B is located at $10 \mathrm{~mm}$ from the profile of the shield and used to obtain the fringe effects at the upside and bottom edges of the proposed structure and conventional structure, and the magnetic field strength curves are shown in Figure 27. The fringe effect also appears at the bottom edge. These waves show that the magnetic field lines are buckled and passed the bottom edge. The maximum value of the increment of magnet field strength is 384.70 for the proposed structure, which is less than the conventional structure.

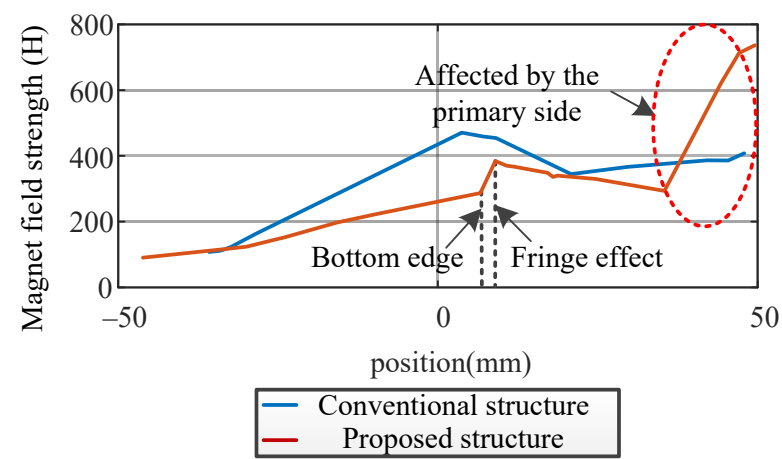

Figure 27. Magnetic field strength curves of the profile of the shields.

According to the above-mentioned finite element analyses, the obtained coupling coefficient $k$ for the proposed structure and conventional structure are 0.489 and 0.456 , respectively.

\subsubsection{Fitting Result Demonstration}

Under the conditions of the same material and relative permeability, based on the structure in Figure 23a, the radius is prolonged as $\left(r_{i}+d_{b}\right)$ in Figure 23b. Substitute the radius and its coefficients into (1), following expression is obtained:

$$
B_{f e}=\sum_{j=0}^{4} a_{j}\left(r_{i}+d_{b}\right)^{4-j},
$$

and the average value of the magnetic field strength is 355.87 , and its maximum value is about 378.16 . The fitting error is about $1.70 \%$, and it is satisfied with the confidence interval. 
Since the magnetic field line cannot be buckled sharply, the actual radius is larger than $\left(r_{i}+d_{b}\right)$, and the actual magnetic field strength is better.

\subsubsection{Horizontal Offset Influence}

The center of the secondary side moves right to $5 \mathrm{~mm}, 10 \mathrm{~mm}, 15 \mathrm{~mm}$ and $20 \mathrm{~mm}$, respectively, to observe performances with some offsets at the horizontal plane, and the results at the test line B of the proposed structure and conventional structure are shown in Figures 28-31, respectively. According to these distribution diagrams, the received magnet fields are gathered into the right half of the shield with the movements of the secondary side. For the conventional structure, the fringe effects in Figure 29 are not changed obviously when compared to the curve in Figure 26.

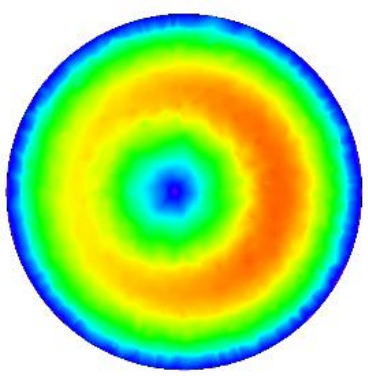

(a)

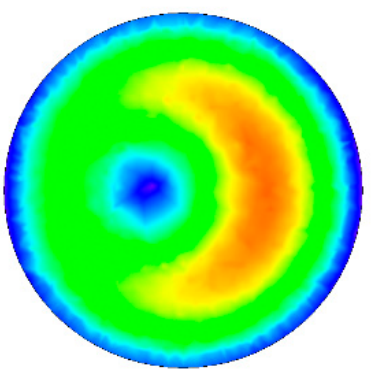

(c)

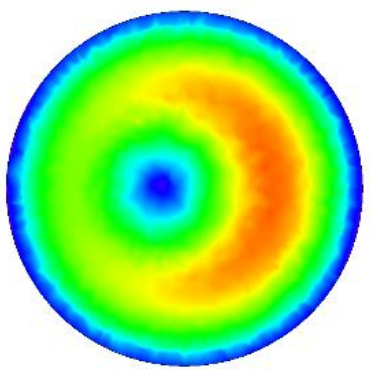

(b)

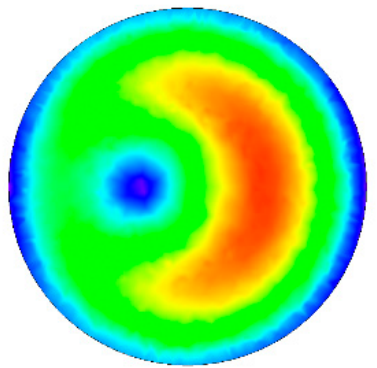

(d)

Figure 28. Distribution diagrams of magnetic field strength with the conventional structure and different offsets of the secondary coil. (a) $5 \mathrm{~mm}$. (b) $10 \mathrm{~mm}$. (c) $15 \mathrm{~mm}$. (d) $20 \mathrm{~mm}$.

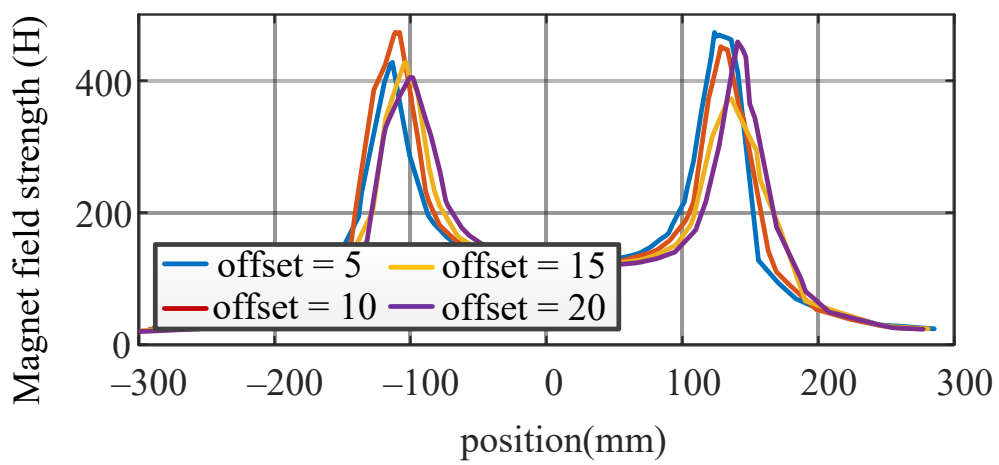

Figure 29. Magnetic field strength curves with the conventional structure and different offsets of the secondary coil. 


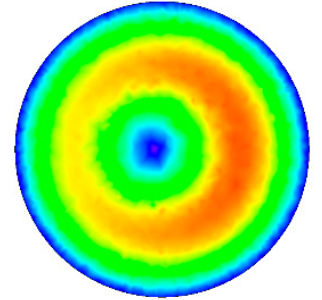

(a)

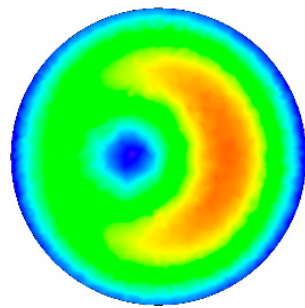

(c)

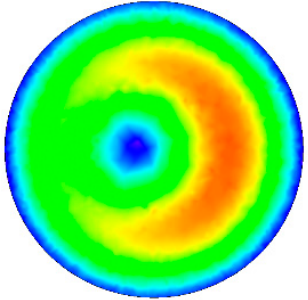

(b)

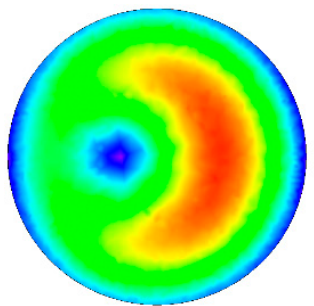

(d)

Figure 30. Distribution diagrams of magnetic field strength with the proposed structure and different offsets of the secondary coil. (a) $5 \mathrm{~mm}$. (b) $10 \mathrm{~mm}$. (c) $15 \mathrm{~mm}$. (d) $20 \mathrm{~mm}$.

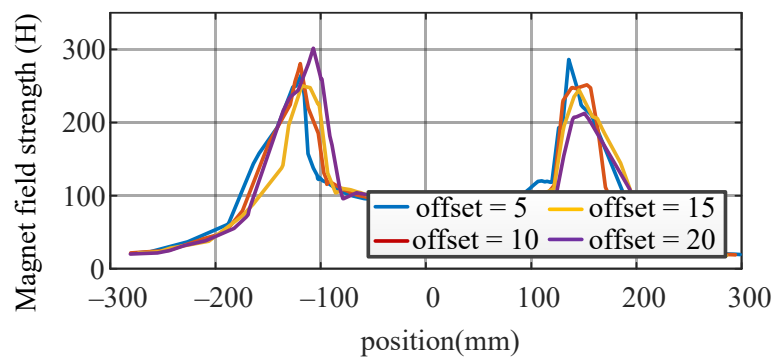

Figure 31. Magnetic field strength curves with the proposed structure and different offsets of the secondary coil.

The gathered magnet fields have similar trends with the movements compared with the conventional structure, and the proposed structure has lower increments of magnet field strength under the same conditions. The magnetic field strength increments at the left edge of the shields are increased gradually because the left edge moves into the receiving range with the dense magnet field lines. On the other hand, the increments of the right edge are decreased because it moves far from the receiving range.

The coupling coefficients for two structures are shown in Figure 32 with different offsets. The average values are 0.4732 and 0.4619 for the proposed and conventional structures, respectively, and a larger coupling coefficient is obtained by the proposed structure. The proposed structure can fully resist the horizontal offset.

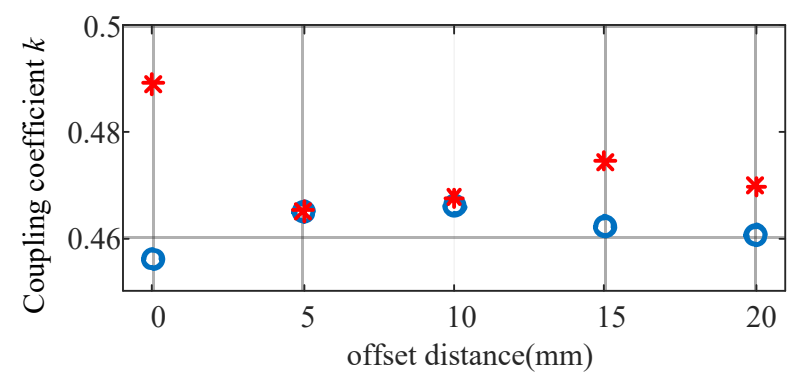

Figure 32. Coupling coefficient curves with the two structures and different offsets of the secondary coil. 
The results with larger offsets, including $30 \mathrm{~mm}$ and $40 \mathrm{~mm}$, are shown in Figures 33 and 34 for the two structures of the shield. Comparing with the curves with $10 \mathrm{~mm}$ and $20 \mathrm{~mm}$ offsets, as shown in the figure, the magnet field strength at the left side is increased for the conventional shield when the offset is $30 \mathrm{~mm}$, and decreased when the offset is $40 \mathrm{~mm}$. The magnet field strengths are continuously decreased with the increment of the offset. The changes of the magnet field strength for the proposed structure are not obviously compared with the conventional structure, and the maximum increment appeared when the offset is $20 \mathrm{~mm}$, as in Figure 31. The magnet field strengths at the right side of the two shields are continuously decreased with the increment of the offset.

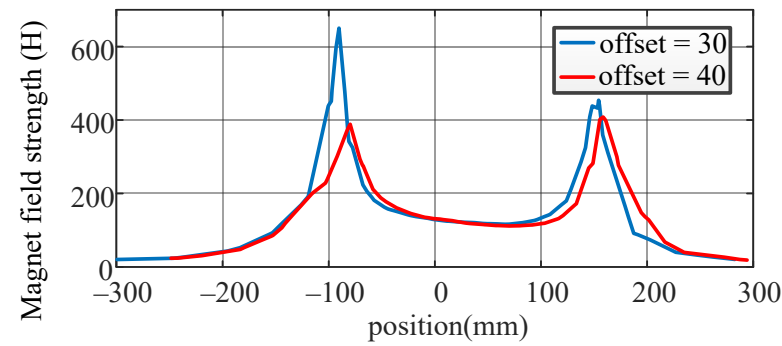

Figure 33. Magnetic field strength curves with the conventional structure and larger offsets of the secondary coil.

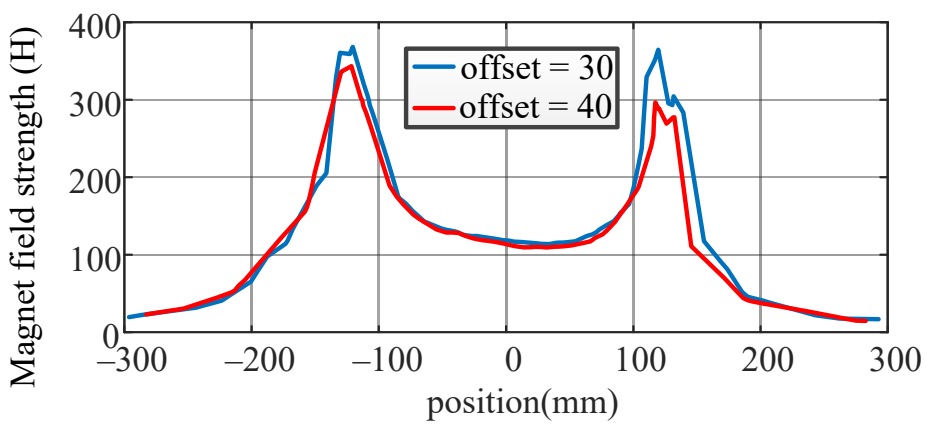

Figure 34. Magnetic field strength curves with the proposed structure and larger offsets of the secondary coil.

The edge of the shield is entered into the magnetic field covering area of the coil of the primary side when a larger offset has happened; the left-side area influenced by the fringe effect might be flooded by the transferring magnetic field when the secondary side moves to the right. This phenomenon can be observed in Figure 33; the magnetic field strength at the left side is increased sharply when the offset is $30 \mathrm{~mm}$. Since the transferring magnet field is decreased at the center of the primary coil, the magnet field strength of the secondary side is decreased when the edge is closing into the center of the primary coil. This phenomenon can also be observed in Figure 33, where the magnet field strength is decreased at the left side when the offset is $40 \mathrm{~mm}$. There is no doubt that these phenomena have also appeared for the proposed shield, but the curves are not obviously changed. This might be because the area covered by the primary coil was moved too early, closing the secondary coil due to the extended part of the shield.

\subsubsection{Circuit Validation}

A circuit simulation was built on the MATLAB/simulink software, and the main parameters of the circuit are listed in Table 5. An uncontrolled rectifier was adopted as the secondary rectifier, and the primary and secondary self-inductions and their mutual inductance were obtained by finite element analysis. Under the same conditions, the current waves for the primary and secondary coils are shown in Figures 35 and 36 for the proposed and conventional strategies, respectively. The energy can transfer to the secondary side of the coupler successfully, with transfer efficiencies of $91.08 \%$ for the 
proposed structure and $90.04 \%$ for the conventional. Since the output voltage and current are uncontrolled, i.e., the system is open-loop, the current amplitude of the secondary coil is larger than the conventional structure.

Table 5. Main circuit parameters.

\begin{tabular}{ccc}
\hline Symbol & Quantity & Values \\
\hline$i_{i}$ & Input current & $10 \mathrm{~A}$ \\
$C_{p}$ & Primary compensation capacity & $120 \mathrm{nF}$ \\
$R_{p c}$ & Resistance of the primary coil & $0.2 \Omega$ \\
$C_{s}$ & Secondary compensation capacity & $53 \mathrm{nF}$ \\
$R_{s c}$ & Resistance of the secondary coil & $0.1 \Omega$ \\
$L_{f}$ & Induction filter & $21.85 \mu \mathrm{H}$ \\
$C_{f}$ & Capacity filter & $16 \mu \mathrm{F}$ \\
$R_{o}$ & Output resistance & $10 \Omega$ \\
\hline
\end{tabular}

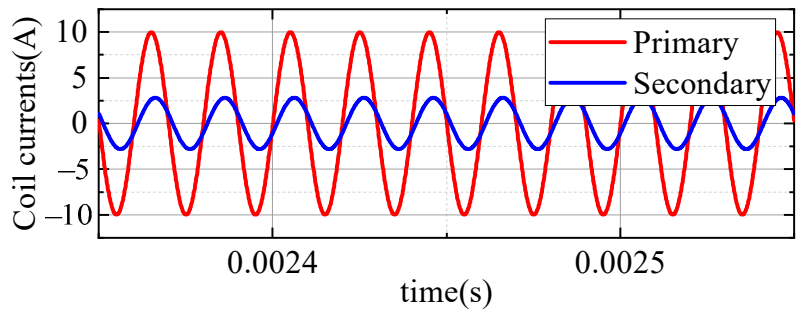

Figure 35. Coupler currents waves with the proposed structure shield.

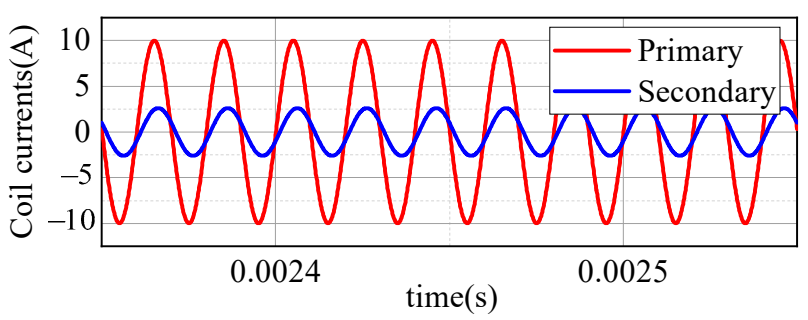

Figure 36. Coupler currents waves with the conventional structure shield.

\section{Conclusions}

Since the fringe effect increases the distances of the magnet field line and wastes the energy of $\mathrm{EV}$, the increment of magnet field strength due to the fringe effect is analyzed in this paper, and its correlations with some parameters including radius, depth, input power and related permeability are obtained by the linear fitting method to estimate the influence of the fringe effect. Based on the obtained correlations, an improved shield structure with an extended part is proposed and used as the secondary shield to prolong the radius indirectly and to reduce the influences of the fringe effect. The advantages of the proposed shield include reduced increment of magnetic field strength, resisting horizontal offset and increased transfer efficiencies, which the results have testified to and verified, as well as the reduced influence of the fringe effect compared with the conventional shield. The effectiveness and correctness of the estimated increment of the magnet field strength and the proposed shield structure are proven by the results of the finite element analyses.

For possible future works, the structure of the shield can be seen as a multi-objective optimization problem based on the obtained curves, and an optimal structure can be obtained by the determined artificial intelligence algorithms, such as the genetic algorithm, the particle swarm optimization (PSO) method and the ant colony algorithm (ANA). Better transfer efficiency could be achieved by these algorithms for the WPT system of EV. 
Author Contributions: Conceptualization, Y.W., Y.T. and Y.S.; methodology, Y.W. and Y.T.; software, Y.S.; validation, Y.W. and Y.S.; data curation, Y.S.; writing-original draft preparation, Y.W.; writingreview and editing, Y.W., Y.T. and Y.S.; supervision, Y.W. and Y.T.; funding acquisition, Y.W. All authors have read and agreed to the published version of the manuscript.

Funding: This research was funded by the Postgraduate Innovation Research Assistant Support Project of Hebei Province, grant number CXZS201907.

Institutional Review Board Statement: Not applicable.

Informed Consent Statement: Not applicable.

Data Availability Statement: Not applicable.

Conflicts of Interest: The authors declare no conflict of interest.

\section{Appendix A}

All of the results of the finite element analyses are summarized as follows. The magnetic field strength curves with different radiuses are shown in Figure A1. 


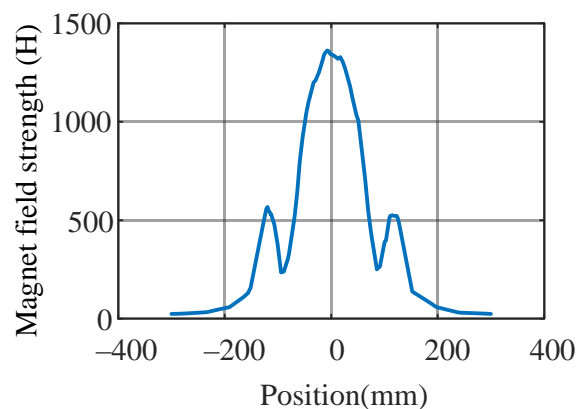

(a)

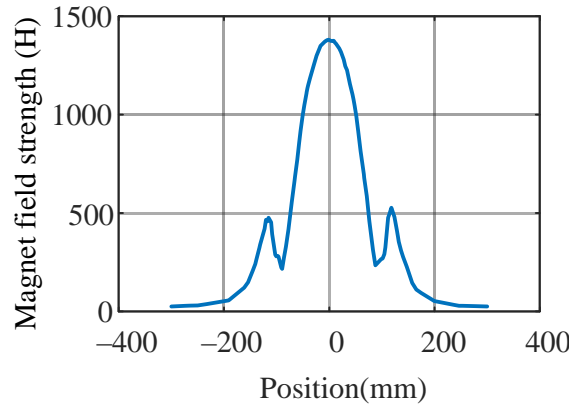

(c)

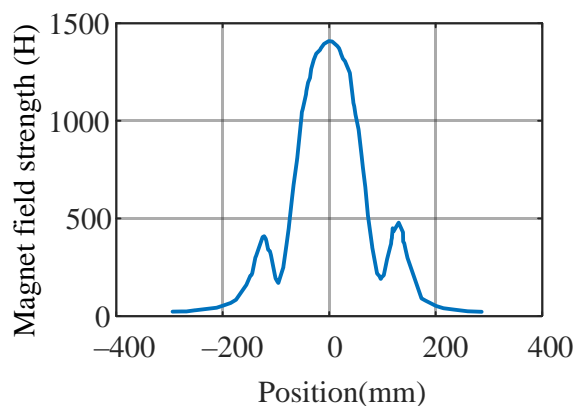

(e)

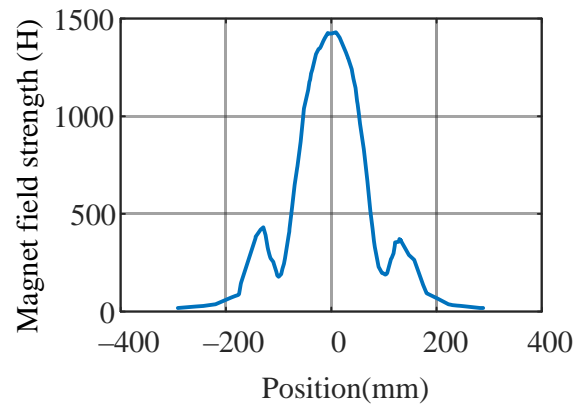

(g)

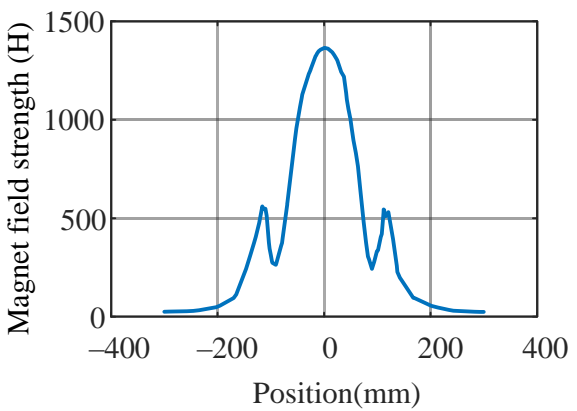

(b)

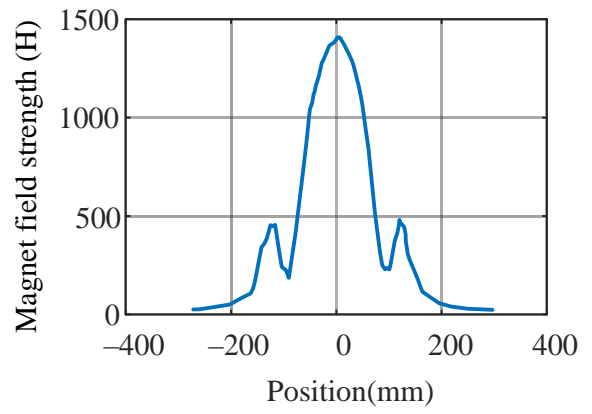

(d)

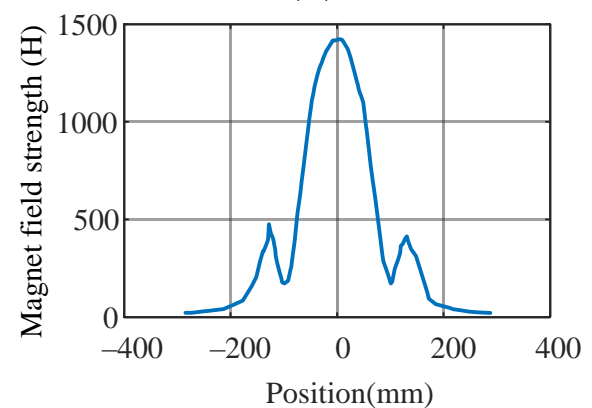

(f)

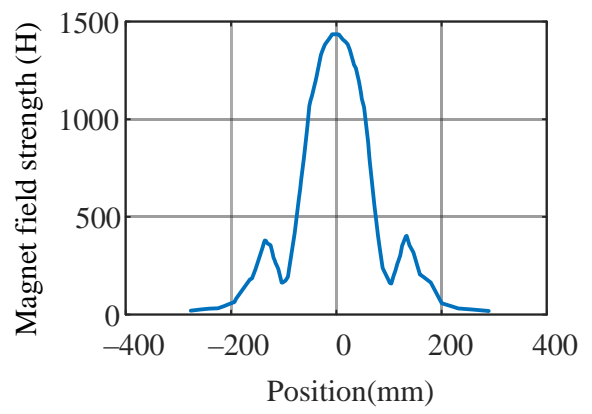

(h)

Figure A1. Magnetic field strength curves with different radiuses. (a) $112 \mathrm{~mm}$. (b) $116 \mathrm{~mm}$. (c) $120 \mathrm{~mm}$. (d) $124 \mathrm{~mm}$. (e) $128 \mathrm{~mm}$. (f) $132 \mathrm{~mm}$. (g) $136 \mathrm{~mm}$. (h) $140 \mathrm{~mm}$.

The magnetic field strength curves with different depths, input powers, MnZn ferrite relative permeabilities and NiZn ferrite relative permeabilities are shown in Figures A2-A5, respectively. 


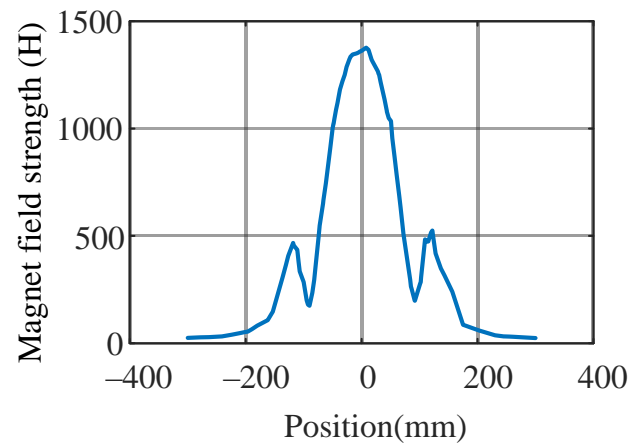

(a)

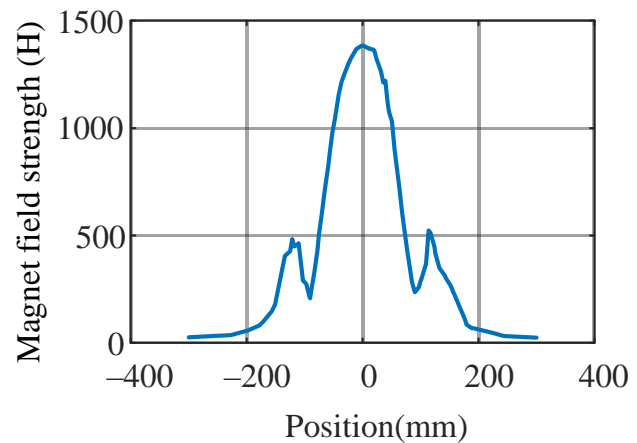

(c)

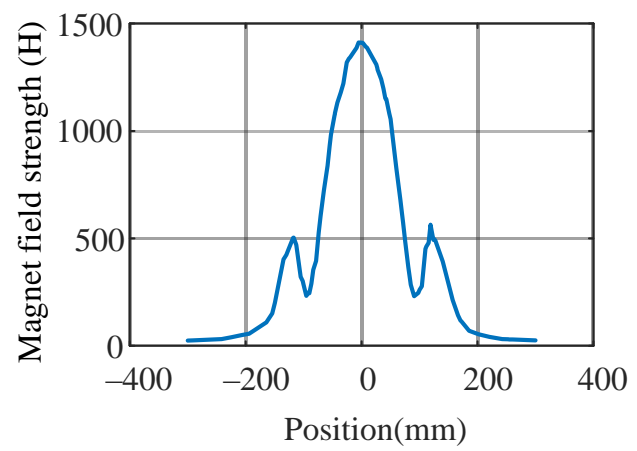

(e)

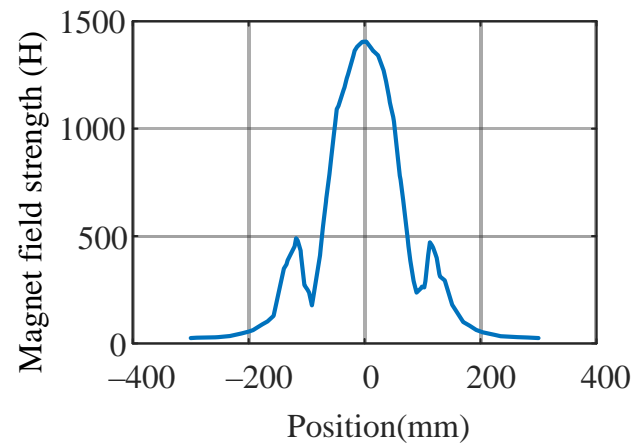

(g)

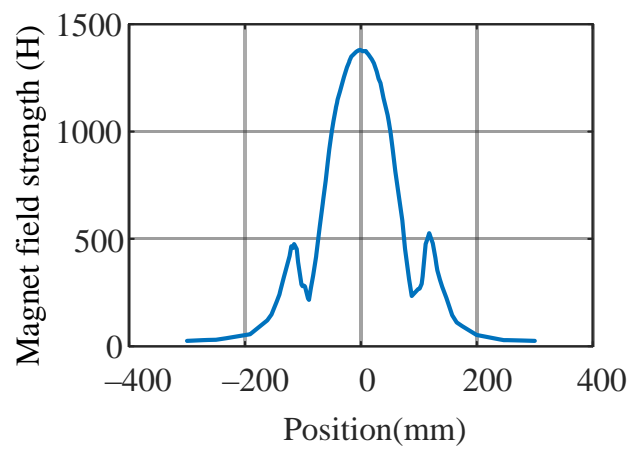

(b)

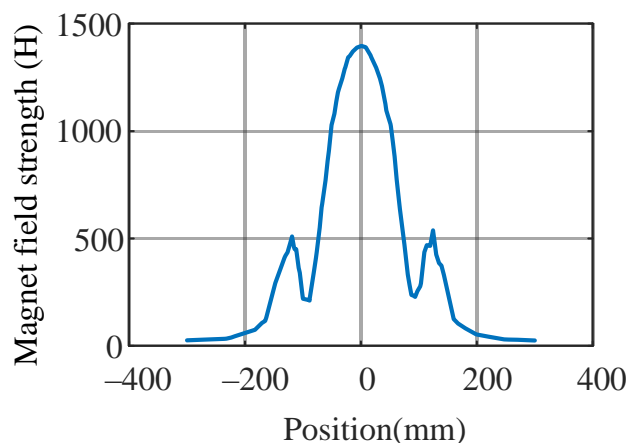

(d)

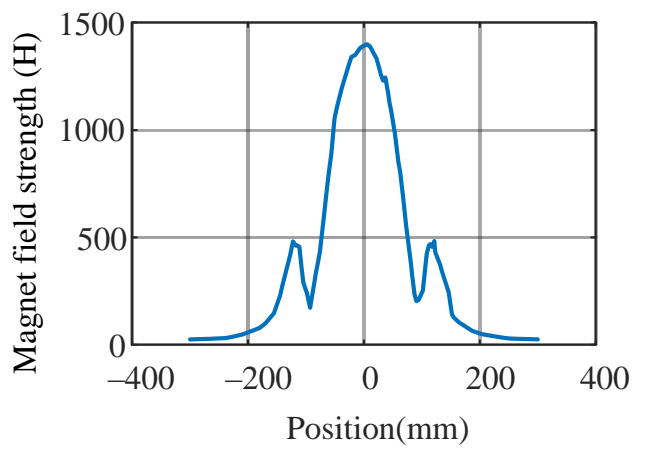

(f)

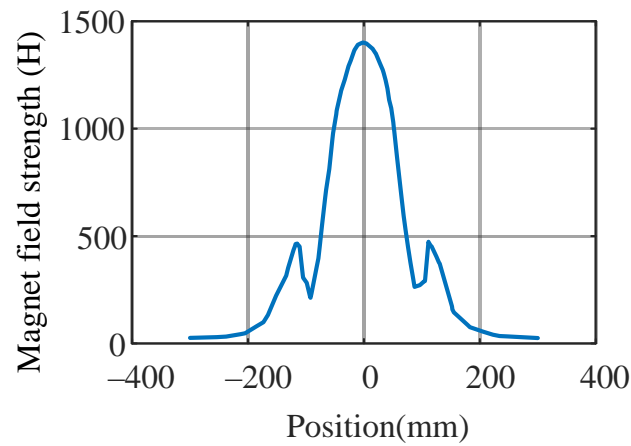

(h)

Figure A2. Magnetic field strength curves with different depths. (a) $0.5 \mathrm{~mm}$. (b) $1.0 \mathrm{~mm}$. (c) $1.5 \mathrm{~mm}$. (d) $2.0 \mathrm{~mm}$. (e) $2.5 \mathrm{~mm}$. (f) $3.0 \mathrm{~mm}$. (g) $3.5 \mathrm{~mm}$. (h) $4.0 \mathrm{~mm}$. 


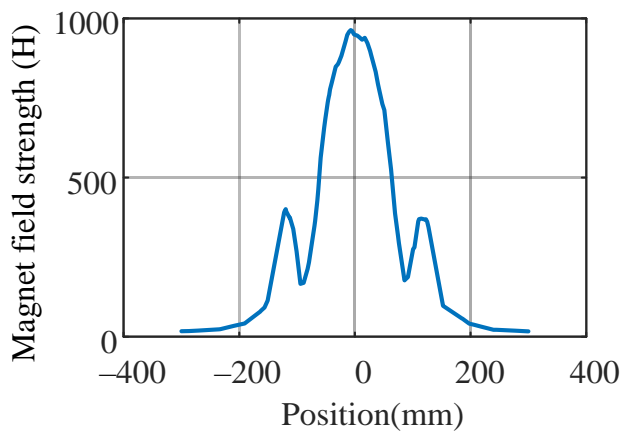

(a)

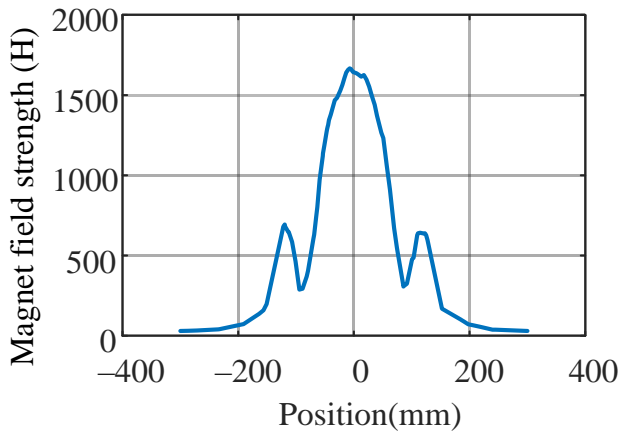

(c)

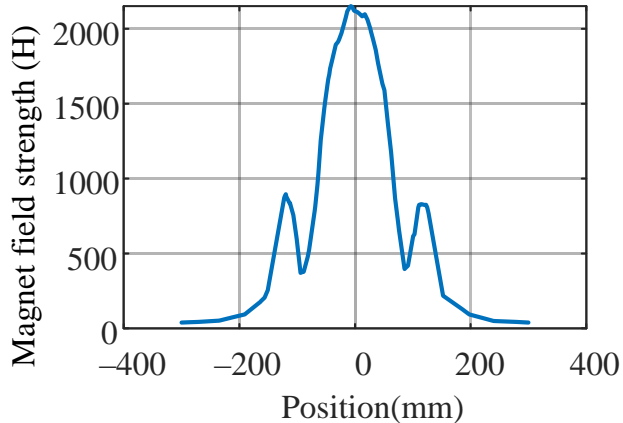

(e)

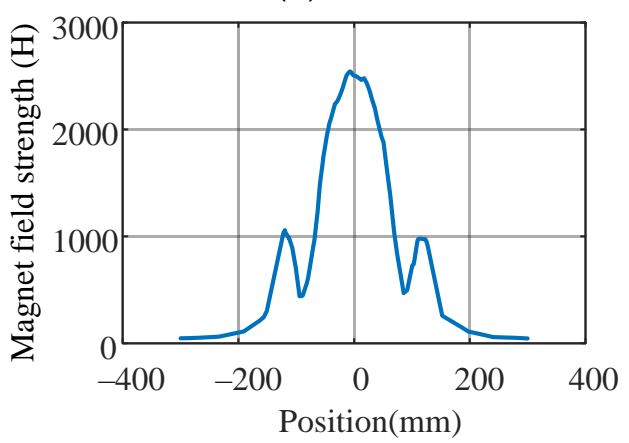

(g)

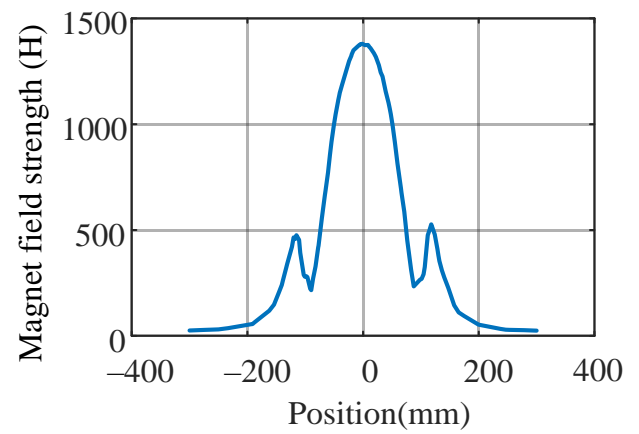

(b)

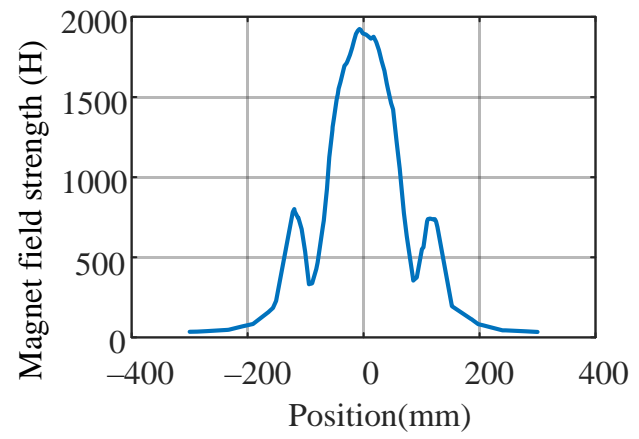

(d)

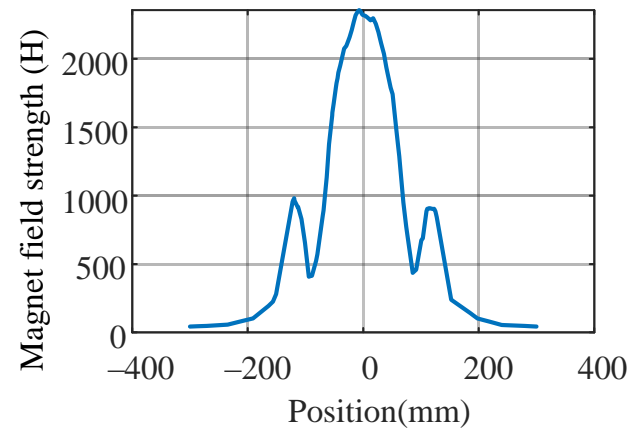

(f)

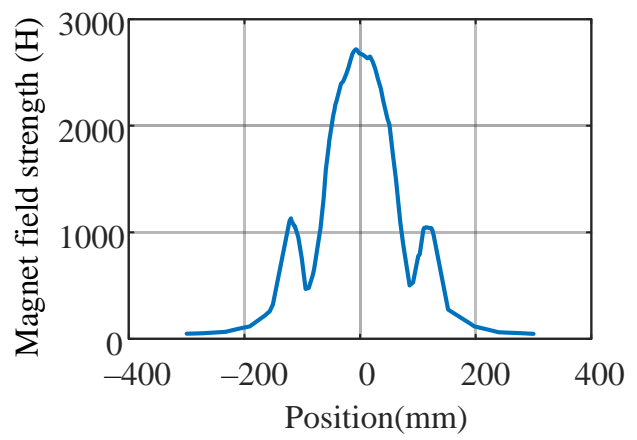

(h)

Figure A3. Magnetic field strength curves with different input powers. (a) $5 \mathrm{~mm}$. (b) $10 \mathrm{~mm}$. (c) $15 \mathrm{~mm}$. (d) $20 \mathrm{~mm}$. (e) $25 \mathrm{~mm}$. (f) $30 \mathrm{~mm}$. (g) $35 \mathrm{~mm}$. (h) $40 \mathrm{~mm}$. 


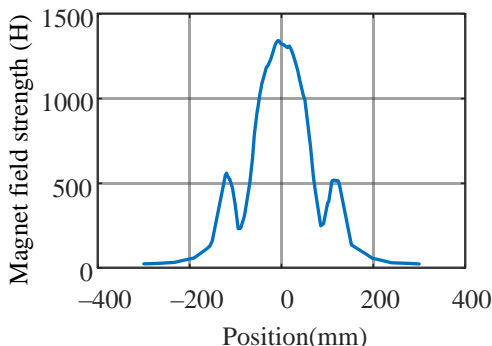

(a)

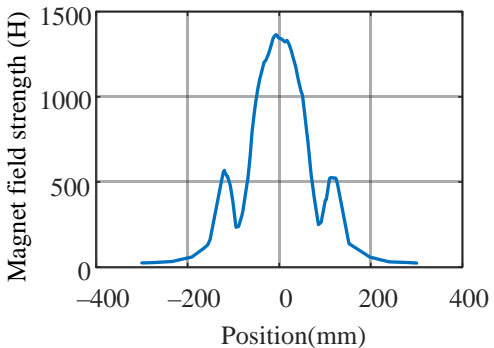

(c)

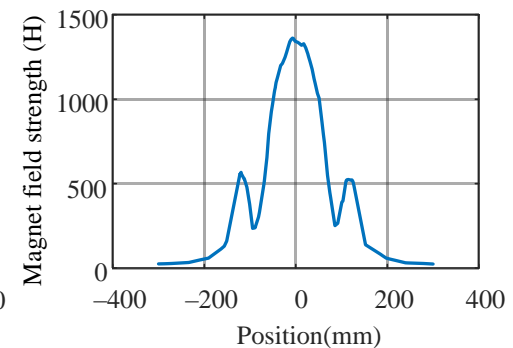

(b)

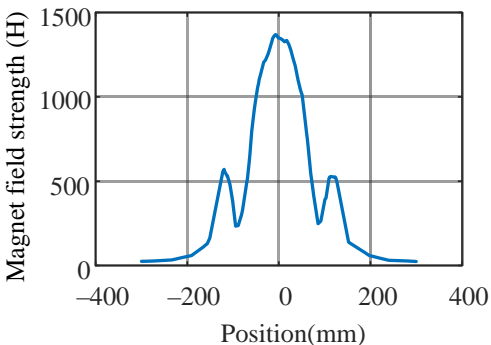

(d)

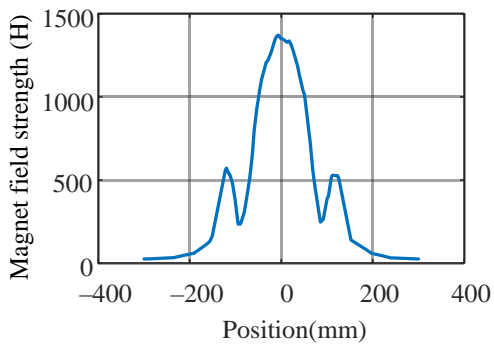

(e)

Figure A4. Magnetic field strength curves with different relative permeabilities of MnZn ferrite. (a) 1200. (b) 2500. (c) 3000. (d) 5000. (e) 7500.

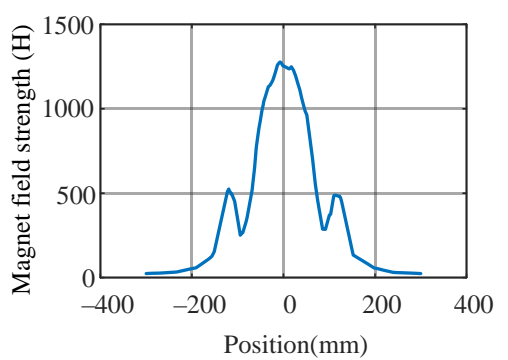

(a)

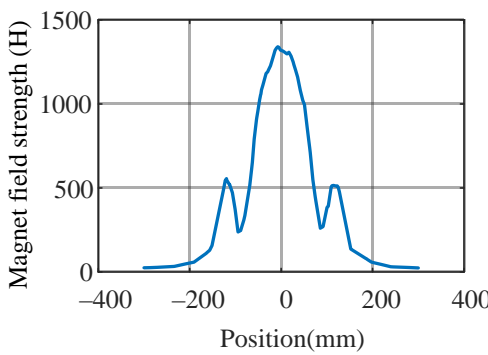

(c)

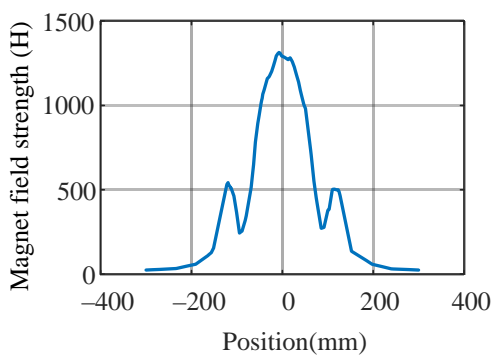

(b)

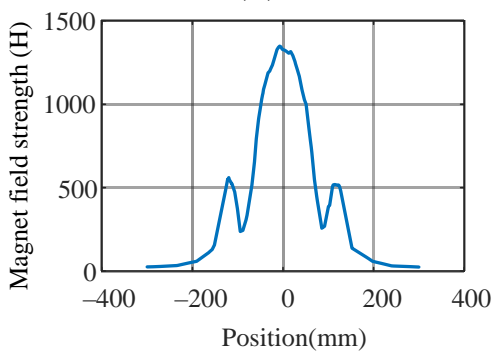

(d)

Figure A5. Magnetic field strength curves with different relative permeabilities of NiZn ferrite. (a) 250. (b) 500. (c) 900. (d) 1200. 


\section{References}

1. Zhu, C.; Yu, J.; Gu, Y.; Gao, J.; Yang, H.; Mai, R.; Li, Y.; He, Z. Analysis and Design of Cost-Effective WPT Systems With Dual Independently Regulatable Outputs for Automatic Guided Vehicles. IEEE Trans. Power Electron. 2021, 36, 6183-6187. [CrossRef]

2. Xia, C.; Wang, W.; Ren, S.; Wu, X.; Sun, Y. Robust Control for Inductively Coupled Power Transfer Systems with Coil Misalignment. IEEE Trans. Power Electron. 2018, 33, 8110-8122. [CrossRef]

3. Campi, T.; Cruciani, S.; Maradei, F.; Feliziani, M. Magnetic Field Mitigation by Multicoil Active Shielding in Electric Vehicles Equipped With Wireless Power Charging System. IEEE Trans. Electromagn. Compat. 2020, 62, 1398-1405. [CrossRef]

4. Zakerian, A.; Vaez-Zadeh, S.; Babaki, A. A Dynamic WPT System with High Efficiency and High Power Factor for Electric Vehicles. IEEE Trans. Power Electron. 2020, 35, 6732-6740. [CrossRef]

5. Yao, Y.; Gao, S.; Mai, J.; Liu, X.; Zhang, X.; Xu, D. A Novel Misalignment Tolerant Magnetic Coupler for Electric Vehicle Wireless Charging. IEEE J. Emerg. Sel. Top. Ind. Electron. 2021, early access. [CrossRef]

6. Songcen, W.; Bin, W.; Xiaokang, W.; Chong, X.; Jinxing, X.; Weimei, G.; Jiaqi, X. Electromagnetic shielding design for magnetic coupler of N-type dynamic electric vehicle wireless power transfer systems. In Proceedings of the 2019 22nd International Conference on Electrical Machines and Systems (ICEMS), Harbin, China, 11-14 August 2019.

7. Xiang, L.; Li, X.; Tian, J.; Tian, Y. A Crossed DD Geometry and Its Double-Coil Excitation Method for Electric Vehicle Dynamic Wireless Charging Systems. IEEE Access 2018, 6, 45120-45128. [CrossRef]

8. Zaheer, A.; Hao, H.; Covic, G.A.; Kacprzak, D. Investigation of Multiple Decoupled Coil Primary Pad Topologies in Lumped IPT Systems for Interoperable Electric Vehicle Charging. IEEE Trans. Power Electron. 2015, 30, 1937-1955. [CrossRef]

9. Tejeda, A.; Kim, S.; Lin, F.Y.; Covic, G.A.; Boys, J.T. A Hybrid Solenoid Coupler for Wireless Charging Applications. IEEE Trans. Power Electron. 2019, 34, 5632-5645. [CrossRef]

10. Kim, S.; Covic, G.A.; Boys, J.T. Tripolar Pad for Inductive Power Transfer Systems for EV Charging. IEEE Trans. Power Electron. 2017, 32, 5045-5057. [CrossRef]

11. Ahmad, A.; Alam, M.S.; Mohamed, A.A.S. Design and Interoperability Analysis of Quadruple Pad Structure for Electric Vehicle Wireless Charging Application. IEEE Trans. Transp. Electrif. 2019, 5, 934-945. [CrossRef]

12. Li, Y.; Zhao, J.; Yang, Q.; Liu, L.; Ma, J.; Zhang, X. A Novel Coil with High Misalignment Tolerance for Wireless Power Transfer. IEEE Trans. Magn. 2019, 55, 1-4. [CrossRef]

13. Li, Y.; Jiang, S.; Liu, J.M.; Ni, X.; Wang, R.; Ma, J.N. Maximizing Transfer Distance for WPT via Coupled Magnetic Resonances by Coupling Coils Design and Optimization. IEEE Access 2020, 8, 74157-74166. [CrossRef]

14. Liu, F.; Ding, Z.; Fu, X.; Kennel, R.M. Parametric Optimization of a Three-Phase MCR WPT System With Cylinder-Shaped Coils Oriented by Soft-Switching Range and Stable Output Power. IEEE Trans. Power Electron. 2020, 35, 1036-1044. [CrossRef]

15. Hwang, Y.J.; Jang, J.Y. Design and Analysis of a Novel Magnetic Coupler of an In-Wheel Wireless Power Transfer System for Electric Vehicles. Energies 2020, 13, 332. [CrossRef]

16. Chen, H.; Qian, Z.; Zhang, R.; Zhang, Z.; Wu, J.; Ma, H.; He, X. Modular Four-Channel 50 kW WPT System With Decoupled Coil Design for Fast EV Charging. IEEE Access 2021, 9, 136083-136093. [CrossRef]

17. Zhang, Y.; Wang, L.; Guo, Y.; Tao, C. Null-Coupled Magnetic Integration for EV Wireless Power Transfer System. IEEE Trans. Transp. Electrif. 2019, 5, 968-976. [CrossRef]

18. Liu, Y.; Madawala, U.K.; Mai, R.; He, Z. Zero-Phase-Angle Controlled Bidirectional Wireless EV Charging Systems for Large Coil Misalignments. IEEE Trans. Power Electron. 2020, 35, 5343-5353. [CrossRef]

19. Zhang, X.; Zhang, Y.; Zhang, Z.; Li, M. Mode Conversion and Structure Optimization of Quadrature Coils for Electric Vehicles Wireless Power Transfer. IEEE Trans. Energy Convers. 2020, 35, 575-590. [CrossRef]

20. Zaheer, A.; Kacprzak, D.; Covic, G.A. A bipolar receiver pad in a lumped IPT system for electric vehicle charging applications. In Proceedings of the 2012 IEEE Energy Conversion Congress and Exposition (ECCE), Raleigh, NC, USA, 15-20 September 2012; pp. 283-290.

21. Choi, S.Y.; Gu, B.W.; Jeong, S.Y.; Rim, C.T. Advances in Wireless Power Transfer Systems for Roadway-Powered Electric Vehicles. IEEE J. Emerg. Sel. Top. Power Electron. 2015, 3, 18-36. [CrossRef]

22. Nagasaki, Y.; Solovyov, M.; Gömöry, F. Experimental and Numerical Investigation of Shielding Performance of Superconducting Magnetic Shields Using Coated Conductor Tapes. IEEE Trans. Appl. Supercond. 2018, 28, 1-5. [CrossRef]

23. Zhang, W.; Yang, Q.; Li, Y.; Lin, Z.; Yang, M.; Mi, M. Comprehensive Analysis of Nanocrystalline Ribbon Cores in High-PowerDensity Wireless Power Transfer Pads for Electric Vehicles. IEEE Trans. Magn. 2021. [CrossRef]

24. Kvitkovic, J.; Patel, S.; Pamidi, S. Magnetic Shielding Characteristics of Hybrid High-Temperature Superconductor/Ferromagnetic Material Multilayer Shields. IEEE Trans. Appl. Supercond. 2017, 27, 1-5. [CrossRef]

25. Wei, Y.; Tian, Y. A Weighting factor online tuning method based PSO algorithm for MPTC strategy of PMSM. In Proceedings of the 2021 IEEE 12th Annual Information Technology, Electronics and Mobile Communication Conference (IEMCON), Vancouver, BC, Canada, 27-30 October 2021. 